\title{
含非典型性生色团的发光聚合物
}

\author{
黄田 ${ }^{a}$ 汪昭昒 ${ }^{a}$ 秦安军 ${ }^{a}$ 孙景志*, $a$ 唐本忠 $*, b$ \\ ( ${ }^{a}$ 浙江大学 高分子合成与功能构造教育部重点实验室 高分子科学与工程学系 杭州 310027) \\ ( ${ }^{b}$ 香港科技大学化学系 香港九龙清水湾)
}

\begin{abstract}
摘要 发光聚合物一般是由具有大 $\pi$ 电子系统的共轭基元作为发光单元, 通过共价键连接而成的高分子. 近年来, 研究 者发现: 另一类仅含有脂肪胺、羰基、酯基、酰胺等传统意义上的助色团的聚合物在适当条件下也能发射强的荧光. 树 枝状聚酰胺胺(PAMAM) 和超支化聚酰胺胺 ( $h b$-PAMAM) 是最早和最广泛被研究的含非典型性荧光生色团的聚合物. 最 近, 这类聚合物被扩展到含有叔胺基元的聚氨酯、聚醚酰胺、聚腿体系. 这些体系的生色团被认定为其结构中的叔胺 基元, 叔胺的氧化是荧光产生的根源. 同时, 也有文献报道马来酸酤与醋酸乙烯酯交替共聚物、异丁烯与顺丁烯二酸䣶 共聚物、聚多糖动态高分子、聚酰腙以及通过 RAFT 试剂制备的含聚三硫碳酸酯的多嵌段共聚物等也可以发射荧光. 这 些聚合物的一个共同特点是结构中不含叔胺基元，而仅含羰基和酷基，其发光机理通常用多个羰基聚集效应或羰基和 苯环之间的相互作用来解释.
\end{abstract}

关键词 生色团; 叔胺; 羰基; 菼光; 超支化聚酰胺胺

\section{Luminescent Polymers Containing Unconventional Chromophores}

Huang, Tian ${ }^{a} \quad$ Wang, Zhaoyang $^{a} \quad$ Qin, Anjun ${ }^{a} \quad$ Sun, Jing Zhi*a $\quad$ Tang, Ben Zhong*,b

$\left({ }^{a}\right.$ MOE Key Laboratory of Macromolecule Synthesis and Functionalization, Department of Polymer Science and Engineering, Zhejiang University, Hangzhou 310027, China)

( ${ }^{b}$ Department of Chemistry, Institute of Molecular Functional Materials, the Institute for Advanced Study (IAS), The Hong Kong University of Science \& Technology, Clear Water Bay, Kowloon, Hong Kong, China)

\begin{abstract}
Luminescent polymers are referred to as conjugated polymers, which are constructed by $\pi$-aromatic building blocks functioning as emitting units. But in recent years, it has been found that a few kinds of polymers only containing auxochromophores or unconventional chromophores such as aliphatic tertiary amine, carbonyl, ester, and amide demonstrate strong luminescence under proper conditions. Poly(amido amine) (PAMAM) dendrimers and hyperbranched poly(amido amine)s are the first reported and most investigated luminescent polymers containing unconventional chromophores. Lately, this kind of polymers have been extended to hyperbranched poly(amino ester)s ( $h b$-PAEs), hyperbranched poly(ether amide)s ( $h b$-PEAs), and polyurea dendrimers (PUREs) containing tertiary amine moieties. The luminogen of PAMAMs, $h b$-PAEs, $h b$-PEAs and PUREs is associated with the $N$-branched tertiary amine moiety and the oxidation of the tertiary amine is assigned to the emitting source. Meanwhile, some distinct polymers had been also reported to be luminescent. Poly[(maleic anhydride)-alt-(vinyl acetate)], polyisobutene succinic anhydrides, glycodynamer analogues of poly(acrylhydrazone)s and multiblock polymer derived by poly(trithiocarbonate) mediated reversible addition-fragmentation chain transfer (RAFT) polymerization of $\mathrm{N}$-isopropyl-acrylamide. A common feature of these polymers is that only carbonyl and ester groups rather than tertiary amine are involved in the polymer structure. Aggregation of multiple carbonyl groups induced emission is usually adopted to explain the mechanism of the emission, and the interaction between carbonyl and phenyl groups was also used to explain the unconventional emission.
\end{abstract}

Keywords chromophore; tertiary amine; carbonyl; fluorescence; hyperbranched poly(amido amine)

\section{1 引言}

光电功能高分子已经发展成为高分子科学研究领 域一个充满活力的重要分支 ${ }^{[1]}$. 光电功能高分子与普通 高分子的根本区别在于化学结构的不同, 以发光高分子 为例, 通常有两种类型. 一类是主链高分子, 由具有大 $\pi$ 电子系统的共轭基元通过共价键连接而成, 这类高分
子又称共轭高分子; 聚噻吩、聚对苯乙烯撑、聚芴都是 常见体系. 另一类是侧链高分子, 其主链是饱和链, 侧 链连接具有光电活性的功能基团, 聚乙烯基咔唑就是其 典型代表. 发光高分子已经在电致发光与显示、白光照 明、聚合物太阳能电池等高科技领域显示巨大的应用前 景, 引起了科学界和工商界几十年的关注. 近年来, 另 一类发光高分子渐渐引起研究者的注意. 与经典的发光

*E-mail: sunjz@zju.edu.cn, Tel.: 0571-87953734,Fax: 0571-87953734; tanbenz@ust.hk, Tel.: 0852-23587375; Fax: 0852-23581594.

Received January 15, 2013; published March 15, 2013.

Projects supported by the National Natural Science Foundation of China (No. 21074113) and the Ministry of Science and Technology of China (No. 2013CB834704).

项目受国家自然科学基金(No. 21074113)和科技部 973 项目(No. 2013CB834704)资助. 
高分子相比, 这类发光高分子的结构中不含苯环、噻吩、 芴、咔唑这样的共轭 $\pi$ 电子系统基元，而仅含有脂肪胺、 羰基、酯基、酰胺基等传统意义上的助色团. 但越来越 多的研究结果表明: 在特定条件下, 这类聚合物也能被 激发出强的荧光. 由于这类高分子在化学结构上更接近 普通高分子, 具有良好的亲水性、链柔性、结构可调性, 所以在化学制备、环境友好、生物荧光成像等方面表现 出诸多优势. 本文将以聚酰胺胺为代表性体系, 以聚合 物的化学结构和研究者对发光机理的探索为主线, 对这 类发光高分子近十年的研究进展进行综述.

\section{2 聚酰胺胺}

早期报道聚酰胺胺(PAMAM) 发射微弱荧光的是 Demas 和 Crosby ${ }^{[2]}$. 作为树枝状大分子领域开创者, 美 国密西根大学的 Tomalia 教授与其合作者 Goodson 博

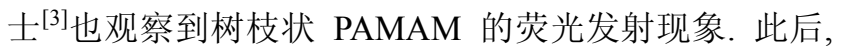
Zheng 等 ${ }^{[4]}$ 在用第四代树枝状聚酰胺胺(PAMAM-G4)作 为模板来制备金纳米粒子的过程中检测到蓝色苂光，但 因为制得的金纳米粒子在紫外激发下可能发射出强的 蓝光, 所以他们把 PAMAM-G4 与金纳米粒子复合体系 的发光直接归结为金纳米粒的发光. 率先报道树枝状 PAMAM 被氧化后发射强烈蓝光现象的是德克萨斯大 学奥斯汀分校和韩国仁川大学化学系 Bard 研究小组, 该组研究者 Lee 等 ${ }^{[5]}$ 于 2004 年报道: 外围羟基化的 PAMAM-G4-OH 和 PAMAM-G2-OH 在 $\left(\mathrm{NH}_{4}\right)_{2} \mathrm{~S}_{2} \mathrm{O}_{8}$ (ASP) 处理或者在环境中放置一段时间后, 即使没有 $\mathrm{Au}$ 粒子 参与, 也能观察到蓝色苂光(图 1A). 但是, 当末端的羟 基换为氨基后，上述现象消失. 因此，他们认为末端羟 基在产生蓝光的过程中起着关键作用，而发光的原因可 能是 ASP 对末端差基的氧化. 同时, 他们在制备包覆 $\mathrm{Au}$ 纳米粒子的 PAMAM-G4-OH 的过程中, 观察到 $\mathrm{Au}(\mathrm{III})$ 被还原成 $\mathrm{Au}(0)$; 而采用 PAMAM-G4- $\mathrm{NH}_{2}$ 代替 PAMAM-G4-OH 后, 则没有 $\mathrm{Au}(0)$ 产生. 他们进一步断 定树枝状 PAMAM 的发光来自末端羟基的氧化.

但是, 名古屋大学的研究小组很快就通过实验推翻 了上述机理. Wang 和 Imae ${ }^{[6]}$ 报道: 在酸性条件下, 末端 为氨基、羟基、羧酸的 PAMAM 树枝状化合物均能发出 强的蓝色苂光, 末端为胺基的 PAMAM-G4 的苂光寿命 是 $1.7 \mathrm{~ns}$ 和 $7.5 \mathrm{~ns}$. 同时, PAMAM-G2 和 PAMAM-G4 的 荧光特性有很大区别, 其强度与 $\mathrm{pH}$ 值直接相关. 在酸 性条件下, PAMAM-G4 的荧光强度远高于 PAMAM-G2. 对于 PAMAM-G4, 当 $\mathrm{pH}$ 低于 6 时, 苂光强度急剧上升 (图 1B); 而 PAMAM-G2 的荧光强度则随 $\mathrm{pH}$ 下降上升 缓慢. 他们推测大致有三个可能的原因: (1)pH 为 6 的这 个转折点刚好与 PAMAM 中叔胺基的 $\mathrm{pK}_{\mathrm{a}}$ 值相应，因此 他们推断可能是由于质子化的叔胺基使得分子内充满 阳离子, 这种强的排斥作用使 PAMAM 的结构变得更加 刚性, 进而使分子链段运动受限. 相比之下, 树形分子
向外生长过程中, 链段变得更加拥挤, PAMAM-G4 比 PAMAM-G2 发光更强. (2) 在酸性条件下使得 PAMAM-G4 中的氢键强度增大, 从而使分子的运动受 到了更强的限制，增加了分子的刚性。(3)树枝状 PAMAM 中的侧基之间可能发生化学反应生成了新的 苂光化学物质.
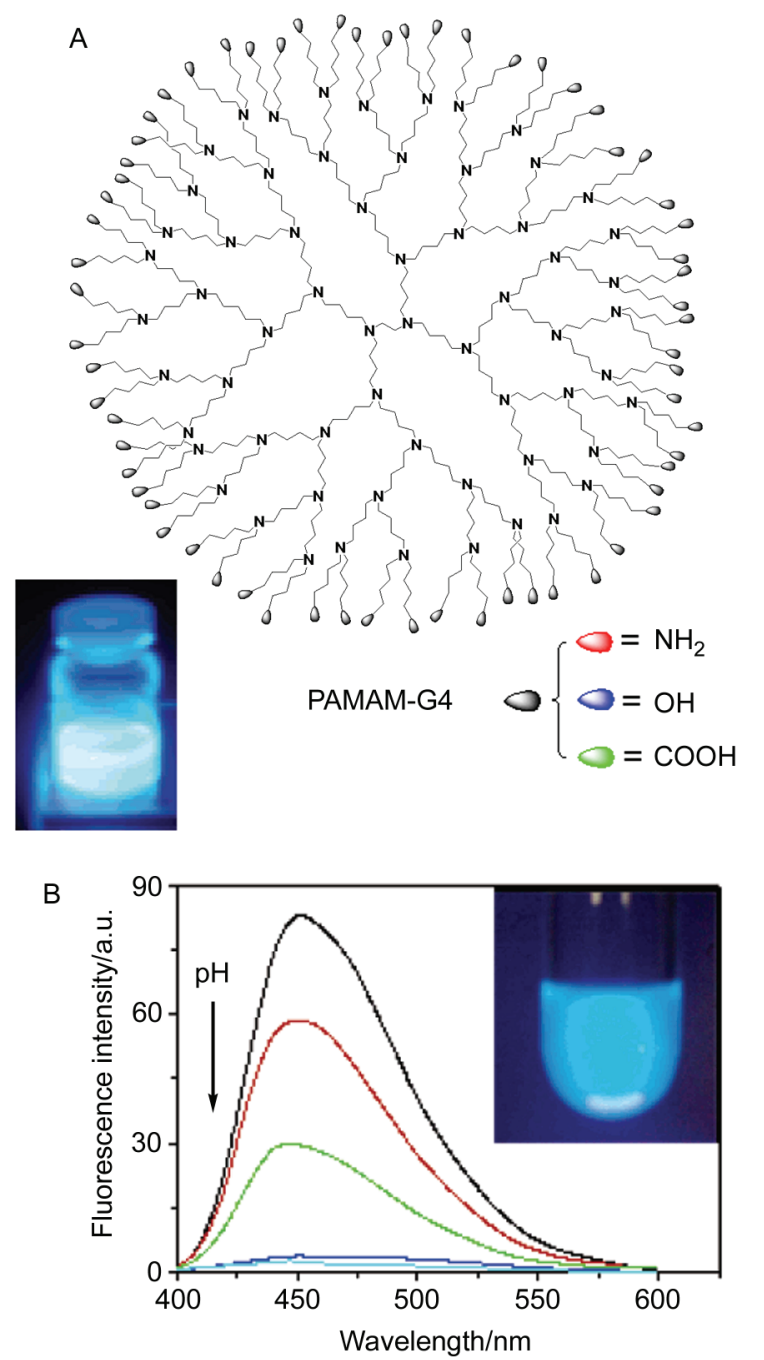

图 1 (A) 带不同外围官能团(氨基、羟基、羧基)PAMAM-G4 的结构 示意图, 内置照片为羟基修饰的 PAMAM-G4 的荧光照片. (B) 羟基修 饰的 PAMAM-G4 水溶液荧光的 $\mathrm{pH}$ 值依赖性 ${ }^{[6]}$

Figure 1 (A) A schematic demonstration of the chemical structure of PAMAM-G4 with different peripheral functional groups (amino, hydroxyl, and carboxylic). (B) $\mathrm{pH}$ dependent fluorescent behavior of hydroxyl functionalized PAMAM-G4 aqueous solution ${ }^{[6]}$

2007 年，复旦大学府寿宽教授课题组也注意到 $h b$-PAMAM 的苂光发射现象. Cao 等 ${ }^{[7]}$ 采用二乙基三胺 与丙烯酸甲酯在不同配料比下进行反应，获得一系列 $h b$-PAMAM(图 2). 尽管化学结构不像树枝状 PAMAM 那样明确，但是产物的物理性质与结构规整的 PAMAM-G2-3 相同, 其发光行为也受 $\mathrm{pH}$ 值、溶剂、聚 合物浓度、端基等因素的影响. 
<smiles>C=CC(=O)OC</smiles><smiles>NCCNCCNCCC(=O)NCCN(CCNC(=O)CCN(CCN)CCN)CCC(=O)NCCN(CCNC(=O)CCN(CCNCCC(=O)N(CCNCCN)CCNCCN)C(=O)CCN(CCN)CCN)C(=O)CCN(CCN)CCNCCC(=O)N(CCC(=O)NCCN)CCC(=O)N(CCN)CCN</smiles>

图 2 用二乙基三胺与丙烯酸甲酯合成 $h b$-PAMAM 的路线图

Figure 2 Synthetic route to $h b$-PAMAM from diethylene triamine and methylacrylate by Michael addition and condensation reactions

此后, Imae 小组 ${ }^{[8]}$ 进一步研究了 PAMAM 的发光机 理，通过荧光寿命和叔胺的质子化程度对比实验作者认 为 PAMAM 内部叔胺基团的氧化是荧光产生的根源. 为 了确证这个机理, 他们把分别能够释放氧气的分子 ASP 和溶致变色分子苯酚蓝负载到 PAMAM-G4 的树枝空隙, 并用三乙胺作为模型分子进行对照研究(图 3). 他们观 察到: 经氧化处理的三乙胺和 PAMAM 溶液在 $365 \mathrm{~nm}$ 的激发下都发射 $440 \sim 460 \mathrm{~nm}$ 的蓝光. 而氧化前后三乙 胺的 ${ }^{1} \mathrm{H}$ NMR 谱和 ${ }^{13} \mathrm{C}$ NMR 谱高度一致, 说明在氧化前 后并没有新的物质生成, 可以认为 PAMAM 中的叔胺基 与发光有直接关系. 把 ASP 或溶致变色分子溴酚蓝作 为客体容纳到树枝状 PAMAM 主体空腔中, 都记录到相 同的蓝光发射, 这说明聚合物的苂光来自大分子内部叔 胺的 $\mathrm{N}$-支化点上, 并且氧或者含氧的分子是必不可少 的. 他们认为三乙胺和其它的 $\mathrm{N}$-支化的聚合物能够在 氧与叔胺支化点处形成过氧自由基或者激基缔合物, 从 而导致瞬态吸收和蓝色发光 ${ }^{[9]}$.

证明脂肪胺中的胺基是发光活性中心的更直接证 据来自 2007 年西班牙巴伦西亚大学 Stiriba 课题组 ${ }^{[10]}$ 对 超支化聚乙二胺 ( $h b$-PEIs) 和线性聚乙二胺 ( $l$-PEIs)发光 行为的研究. 他们比较了两种超支化聚合物和两种线性 聚合物, 分别是 $h b$-PEIs、 $l$-PEI 和端基甲基化的

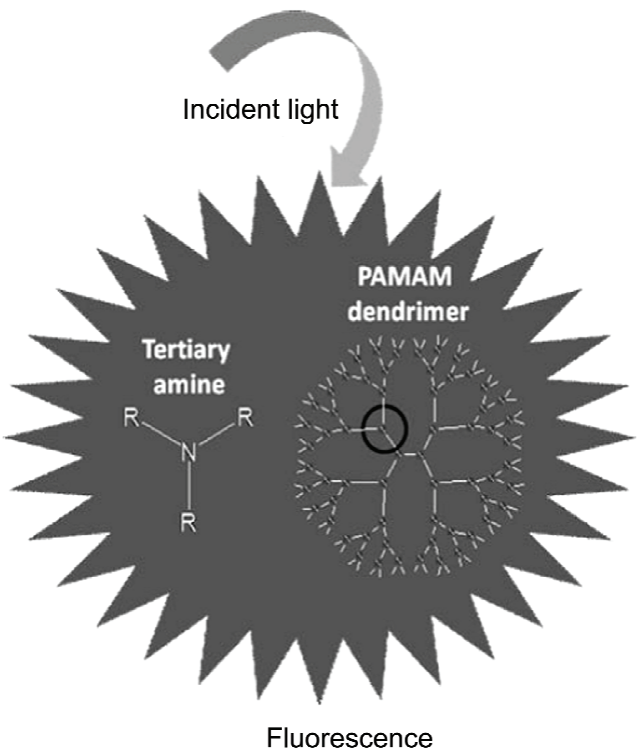

图 3 用三脂肪胺作模型分子研究树枝状 PAMAM 的荧光的示意图, 树枝状大分子内部的叔胺分支点被确定为发光中心 ${ }^{[8]}$

Figure 3 An illustration of the fluorescence of dentritic PAMAM using aliphatic tertiary amine as a model compound, and the N-branch points of tertiary amines inside the dentrimer are assigned to emitting centers ${ }^{[8]}$ 
$h b$-PEIs-Me 和 $l$-PEI-Me. 实验观察到 $l$-PEI 聚合物也能 和 $h b$-PAMAM 一样发出强烈的蓝光(图 4). 不仅如此, 这些 PEI 衍生物的荧光特点和之前的 PAMAM 树形分子 一样具有某些相同性质, 例如氧化和酸化过程都能大大 增强荧光. 此外, 将 PEI 的端基甲基化使荧光增强. 这 些研究结果说明树枝状结构或者超支化结构不是产生 荧光的必要条件, 而脂肪胺基的存在似乎才是不可或缺 的. 2011 年, 台湾国立健康研究院纳米医药研究中心的 Lin 等 ${ }^{[11]}$ 通过核磁共振波谱和 MALDI-TOF 质谱相结合 的技术, 详细研究了树枝状 PAMAM 与 $\mathrm{H}_{2} \mathrm{O}_{2}$ 反应的过 程, 揭示了 PAMAM 荧光的起源不是本征的 PAMAM, 而是被氧化的 PAMAM. 在 $\mathrm{H}_{2} \mathrm{O}_{2}$ 的氧化作用下, PAMAM 通过级联 Cope 消除反应而解体, 产生的碎片 中有一种羟胺片段, 这才是产生荧光的物种(图 5).

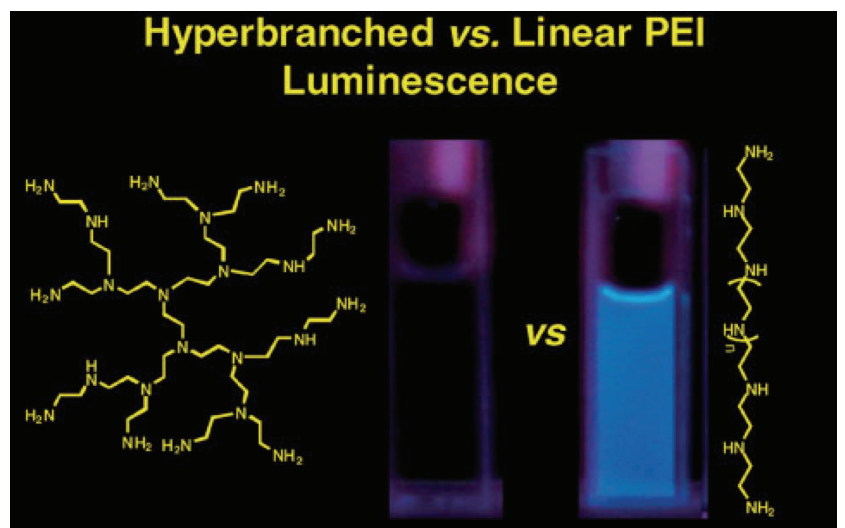

图 4 超支化和线形聚乙二胺的化学结构与发光性质比较 ${ }^{[10]}$

Figure 4 Chemical structure and photoluminescence properties of the hyperbranched polyethylenimine and their linear counterpart ${ }^{[10]}$

尽管 PAMAM 发光的机理一直存在争议, 但是改善 PAMAM 菼光并探索其在生物医学领域的应用的工作 未曾停止. Imae 教授在国立台湾科技大学兼职后, 把树 枝状 PAMAM 体系的研究扩展到固相, 包括把 PAMAM 树枝连接到多孔氧化硅微粒表面, 把树枝状 PAMAM 制 备成图案化的薄膜, 以及把树枝状 PAMAM 通过偶联反 应连接到透明质酸上, 制备纳米微球连接成的亲水网络 结构, 探索在生命科学领域中的应用 ${ }^{[12 ~ 14]}$. 在最近的一 项研究中, Saravanan 和 $\operatorname{Imae}^{[12]}$ 利用氨基和羧基封端的 PAMAM 的亲水性和带电特性把 PAMAM-G4 和 PAMAPM-G4.5 吸附到由亲/疏水材料构筑的图案化表 面, 荧光成像研究结果表明吸附了 PAMAM 的亲水区域 经氧处理后显示出强荧光, 而且荧光强度随着充氧和脱 氧处理而规律性地改变. X-射线光电子能谱表征结果证 明, 充入的氧气与 PAMAM 结构中的叔胺基团而不是酰 胺基团作用.

2009 年, 中国科技大学的潘才元研究小组 ${ }^{[15]}$ 报道 了一种新型可降解的超支化 PAMAM $(h b$-PAMAM). 他 们通过 $N, N^{\prime}$-双(丙烯酰)胱胺和 1-(2-氨基乙基)哌嗪与丙 烯酸酯的 Michael加成聚合反应实现了 $h b$-PAMAM 的双

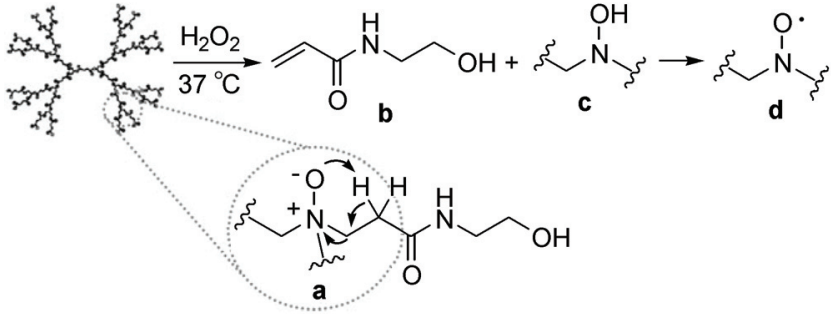

图 5 级联 Cope 消除反应是 PAMAM 解体的可能机理, 其中 $\mathrm{a}$ 是反应 中心, b, c, d 分别是消除反应产生的碎片 ${ }^{[11]}$

Figure 5 A plausible mechanism of PAMAM breakdown is proposed as a cascade of Cope elimination reactions, where a is the reaction center and $b, c, d$ are the residuals of the elimination reactions, respectively ${ }^{[1]]}$

硫键功能化(图 6). 该工作的一个关键创新点设计合成 的 $h b$-PAMAM 结构中的二硫键可被 2-放基乙醇或谷胱 甘肽切断，因此聚合物具有良好的生物可降解性. 他们 观察到在聚合的过程中随着聚合的进行, 聚合物的荧光 强度不断增加，表明分子量增大引起链段聚集或拥挤诱 导了苂光增强. $h b$-PAMAM 在适当波长的激发下发出可 覆盖整个可见光区的荧光. 用波长为 $330 \sim 385,460 \sim$ 490 和 $510 \sim 550 \mathrm{~nm}$ 的光激发, 聚合物溶液分别发射蓝、 绿和红色苂光(图 6B).

2010 年，他们报道了通过 Michael 加成聚合反应一 锅煮合成用外围 $D$-甘露糖功能化的超支化 PAMAMs (M- $h b$-PAMAMs, 图 7) ${ }^{[16]}$. 对比研究发现: 平均分子量 为 17200 的 M- $h b$-PAMAMs 苂光强度比同样测试条件 下未加甘露糖修饰的 $h b$-PAMAMs 提高约 340 倍. 他们 推断 $D$ - 甘露糖是带有 4 个羟基的光学活性化合物, 外围 修饰可能有效地限制了 $h b$-PAMAMs 末端的链运动, 从 而抑制了分子碰撞松弛过程和自淬灭过程，诱导荧光显 著增强. M- $h b$-PAMAMs 外围的甘露糖极易与细菌亲和, 因此将 M- $h b$-PAMAMs 与 E. coli 共同培养得到发荧光的 细菌菌落, 而没有洗净的区域则荧光暗淡. 这个研究为 利用这种特殊荧光高分子进行生物成像和给药示踪研 究打开了方便之门. 接着, 他们在甲醇/水混合溶剂中把 $N, N^{\prime}$-双(丙烯酰)胱胺、1-(2-氨基乙基)哌嗪和 $N$-半乳糖 胺盐酸盐用 Michael 加成分散聚合制得了纳米微粒. 这 种纳米微粒表现出强的苂光发射、光稳定性和宽的光谱 响应范围. 他们与王均教授合作将得到的纳米粒子与肝 癌细胞 HepG2 共孵化, 发现这些纳米粒子无细胞毒性 且能够被 HepG2 表面的唾液酸糖蛋白识别并被胞吞, 从而达到了生物成像的目的 ${ }^{[17]}$.

因为 PEI 衍生物是一类常用的基因载体聚合物, 所 以不难想到 PAMAM 作为聚多胺也可以用于基因载体 以及和 DNA 相关的研究领域. 2010 年，中国科技大学尤 业字与洪春赝教授 ${ }^{[18]}$ 联合报道了基于 PAMAM 构筑的 具有可控生物还原性和刺激响应性的荧光纳米环. 他们 用 1-(2-氨基乙基)哌嗪与 $N, N^{\prime}$-双(丙烯酰)胱胺和 $N, N^{\prime}$ 甲叉二丙烯酰胺共加聚制得新型 $h b$-PAMAMs，聚 
<smiles>C=CC(=O)NCCSSCCNC(=O)C=C</smiles>

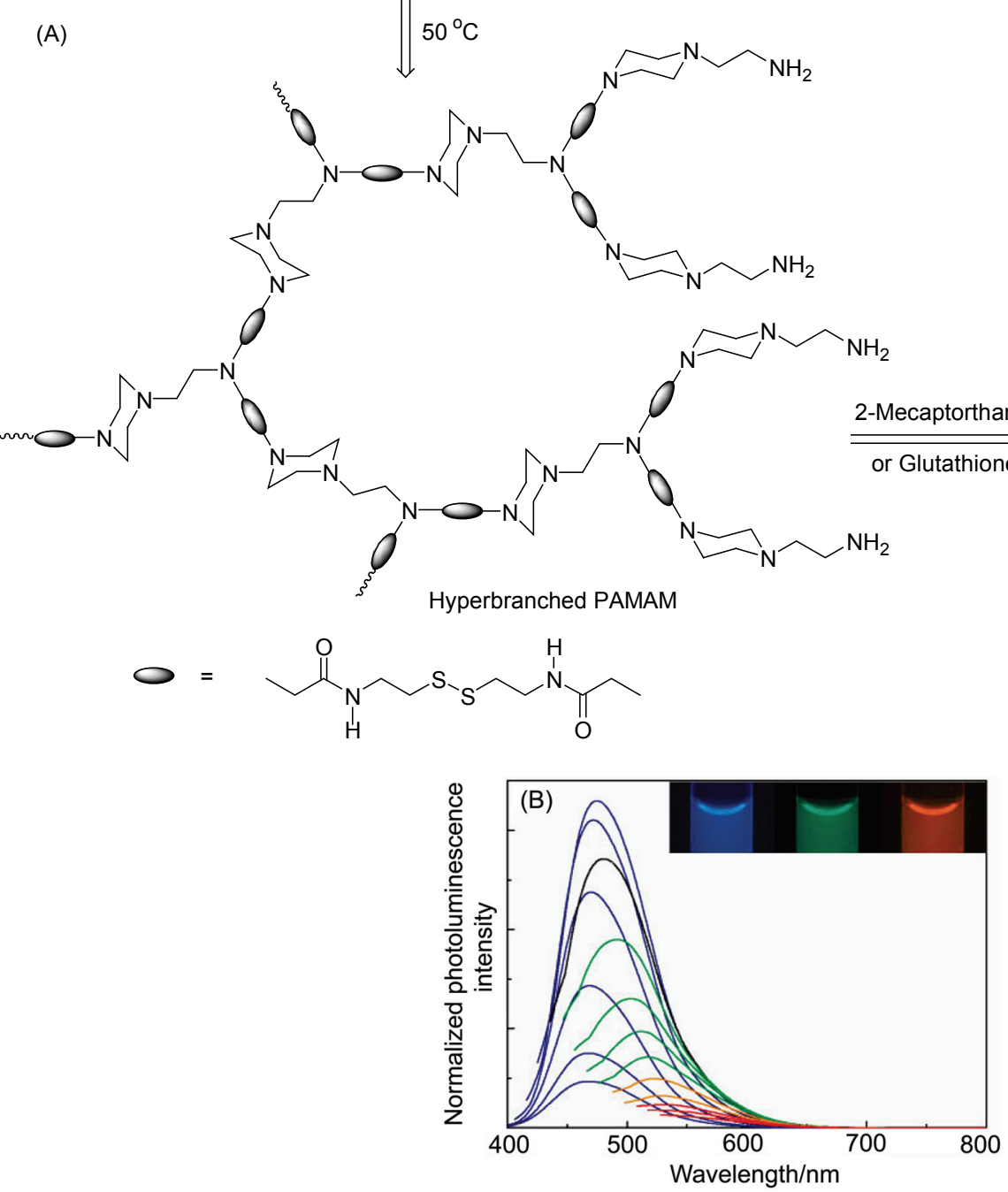

图 6 (A) 含双硫键的可降解 $h b$-PAMAM 的合成与降解路线示意图. (B) $h b$-PAMAM 水溶液在不同激发波长下的荧光光谱与苂光照片 ${ }^{[15]}$

Figure 6 (A) An illustration for the synthetic and breakdown of disulfide-containing $h b$-PAMAM. (B) Fluorescence spectra and images of the aqueous solutions of the derived $h b$-PAMAM excited at different wavelengths ${ }^{[15]}$

合物结构中 $N, N^{\prime}$-双(丙烯酰)胱胺和 $N, N^{\prime}$-甲叉二丙烯酰 胺单元的物质的量比为 $1: 2$ (HPAA12, 图 8A). 研究表 明: HPAA12 能够有效地把质粒 DNA 组装成纳米环结 构, 二硫键分布在纳米环壁上(图 8B, C). 制得的这些纳 米环不仅具有发光性能, 而且具有刺激响应性、生物相 容性和可控生物还原性, 在基因与药物控释和分子影像 学领域都有用武之地.

最近, 上海交通大学朱新远教授和华东师范大学陈 群教授 ${ }^{[19]}$ 合作尝试用 $\beta$ - 环糊精 $(\beta-\mathrm{CD})$ 修饰的 $h b$-PAMAM HPAA- $\beta$-CDs, 作为荧光型非病毒基因控释 载体. 以 $N, N^{\prime}$-甲叉二丙烯酰胺、1-(2-氨基乙基)哌溙和 单-6-脱氧-6-乙二胺基- $\beta$-环糊精为聚合单体, 采用 Michael 加成共聚合方法通过控制单体比例可以制得不 同 $\beta$-CD 含量的 HPAA- $\beta$-CDs(图 9). 与未经 $\beta$-CD 修饰
的 HPAA 相比, HPAA- $\beta$-CDs 具有明显增强的苂光和更 低的细胞毒性. 更重要的是, HPAA- $\beta$-CDs 能够高效地 浓缩 p-DNA, 形成的 HPAA-CD/p-DNA 复合物容易被细 胞快速内吞. HPAA- $\beta$-CDs 自身的发光性可以使复合物 免于荧光染料标记的复杂处理而实现苂光示踪; 在基因 转染过程中, HPAA- $\beta$-CDs 主要处于细胞质中. 同时, HPAA- $\beta$-CDs 中的 $\beta$-CD 还可以盛放药物. 因此他们获 得的复合体系具有控制释放、基因治疗和化学治疗的多 重功能.

\section{3 聚氨基酯、聚醚酰胺与聚脲}

除超支化 PAMAM之外，其它一些含有叔胺和羰基 的聚合物也先后被报道有荧光发射现象. 新加坡国立大 学材料与工程研究所和化学系 Liu 等 ${ }^{[20]}$ 于 2005 年报道 


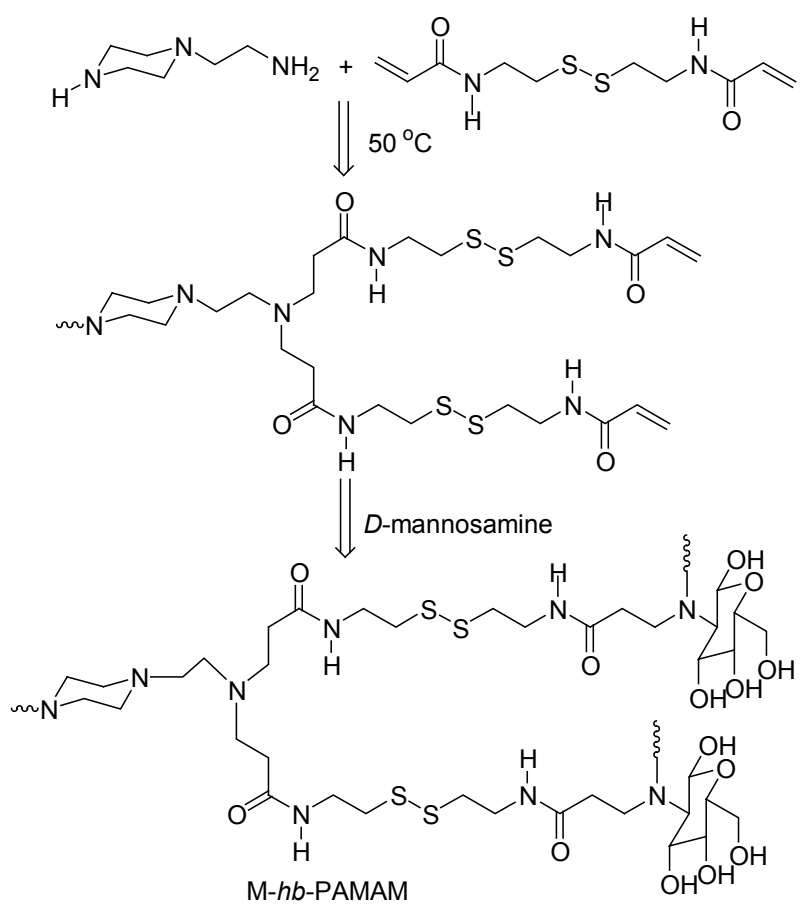

图 7 外围 $D$-甘露糖功能化的超支化 PAMAMs 衍生物合成路线图 Figure 7 An illustration of the synthetic route of $D$-mannose functionalized $h b$-PAMAM

了超支化聚氨基酯 [hyperbranched poly(amino ester), $h b$-PAE]的蓝色发光现象. $h b$-PAE 的合成路线和化学结 构见图 10, Poly(BDA2-AEPZ1)-vinyl 是以丙烯酸酯封端 的前聚物, 它是通过 1-(2-氨基乙基)哌嗪(AEPZ)与双倍 物质的量的 1,4-丁二醇-二丙烯酸酯(BDA)的 Michael 加 成聚合得到的 ${ }^{[21]}$. 将前聚物用乙醇胺、2,3-二差基丙胺 和 AEPZ 后修饰, 分别得到末端基团为单羟基、双羟基 和伯胺基的聚氨基酯 poly(BDA2-AEPZ1)-OH, poly(BDA2-AEPZ1)-(OH $)_{2}$ 和 poly(BDA2-AEPZ1)- $\mathrm{NH}_{2}$. 他们发现, 与 PAMAM 相似, 在中性条件下, 用过硫酸 铵处理或者暴露在空气中三种超支化聚合物均能发出 蓝色荧光. 并且超支化聚合物的荧光发射强度与所处环 境的 $\mathrm{pH}$ 值相关. 当 $\mathrm{pH}$ 从 11.7 到 6.0 时, 发光没有明显 变化; 而当 $\mathrm{pH}$ 从 6.0 到 2.0 时, 发光明显增强. 但不同 于 PAMAM 的是, 发光是 $h b$-PAE 本身的特性, 并不是 来自氧化过程, 氧化过程只能够起到增强荧光的作用. 进一步通过 PAMAM 与 $h b$-PAE 的结构比较, 两者的结 构相似之处在于: 同时存在叔胺基和羰基, 并且拥有树 枝状形态和大量合适的端基. 他们认为这些化学结构是 $h b$-PAE 产生苂光的关键因素.

这个工作的一个重要贡献是发现 $h b$-PAE 发光性能 比 PAMAM 更强, 尽管其机理还不清楚, 但是为设计类 似的苂光聚合物提供了思路. 最近, 潘才元教授课题 组 ${ }^{[2]}$ 利用 $h b$-PAE 的这一特点, 以三颈基乙醇胺(TMEA) 和二丙烯酸乙二醇酯(EGDA)为单体, 经 Michael 加成反 应 11，15，20, $24 \mathrm{~h}$ 得到超支化聚氨基酯 HypET11，

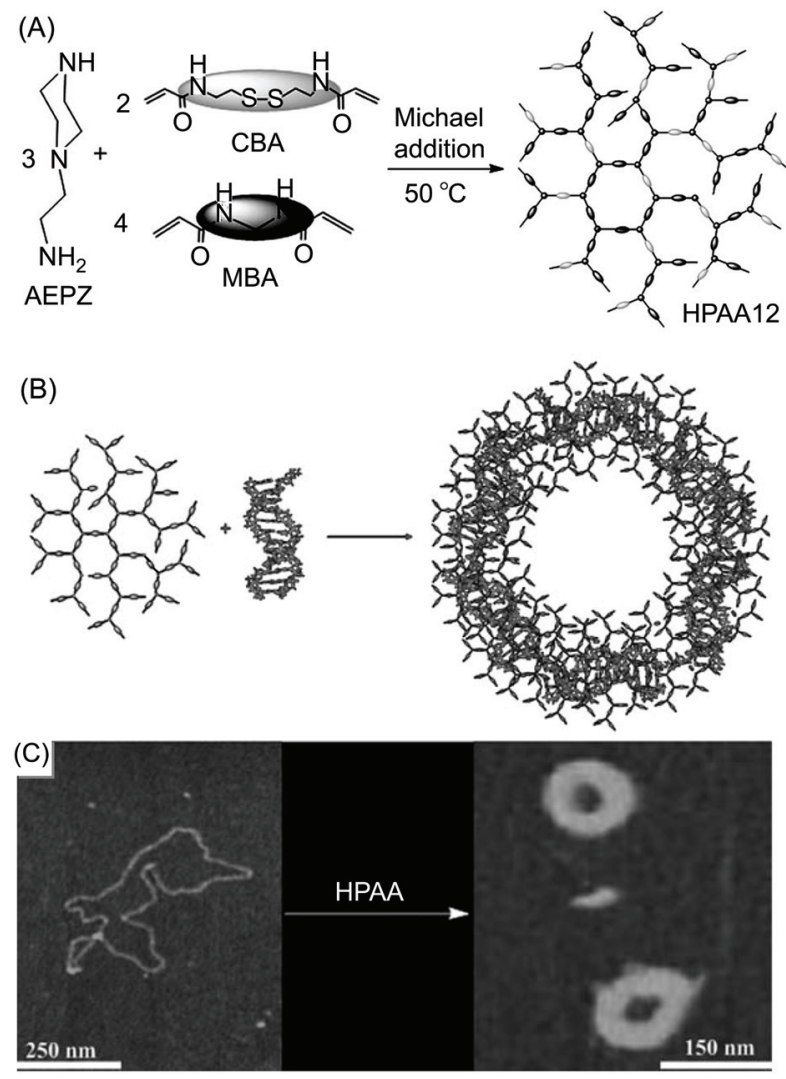

图 8 (A)树枝状 PAMAM(HPAA12)的合成路线. (B)HPAA12 与质粒 DNA 组装成纳米环的示意图. (C) 质粒 DNA 与含双硫键的 HPAA12 组 装前后 AFM 图像 ${ }^{[18]}$

Figure 8 (A) Synthetic route to hyperbranched poly(amido amine) (HPAA12) by Michael addition polymerization. (B) Schematic depiction of formation of the nanoring by the assembly of HPAA12 with plasmid DNA. (C) AFM images of plasmid DNA before and after condensation with disulfide-containing HPAA12 $2^{[18]}$

HypET15, HypET20 和 HypET24, 并深入研究了所得聚 合物的发光性能(图 11). 研究结果表明: 叔胺作为分叉 点的超支化聚氨基酯具有较强的荧光, 溶液的产率最高 可达 $43 \%$; 而且骨架上或者侧链上带有叔胺的线性聚氨 基酯则表现出相对弱的荧光. HypET 的荧光随着聚合物 分子量增大而提高. 用吡喃型半乳糖修饰的 HypET 具 有低的细胞毒性和高的细胞成像亮度. 这项研究再次肯 定了脂肪族叔胺作为超支化聚合物分叉点在发光过程 中的关键作用，验证了 Wryzykowska 等 ${ }^{[23]}$ 提出的脂肪 族叔胺中的氧一胺 “接触型” 给受体复合物是发光中心 的观点，同时也为设计新型细胞成像、生物传感和药物 控释材料提供了借鉴.

羰基和脂肪胺官能团作为潜在的生色团也可以引 入到其它聚合物体系中. 中国科学院长春应用化学研究 所的李悦生研究员等 ${ }^{[24]}$ 在研究聚醚酰胺时 “意外地” 观 察到这类聚合物的苂光发射现象. 研究者分别用丙烯酰 氯和甲基丙烯酰氯与不同的多羟基脂肪伯胺反应，得到 一系列带有多羟基的丙烯酰胺新单体，再提高温度通过 缩聚反应和 Michael 加成聚合反应得到外围羟基覆盖的 


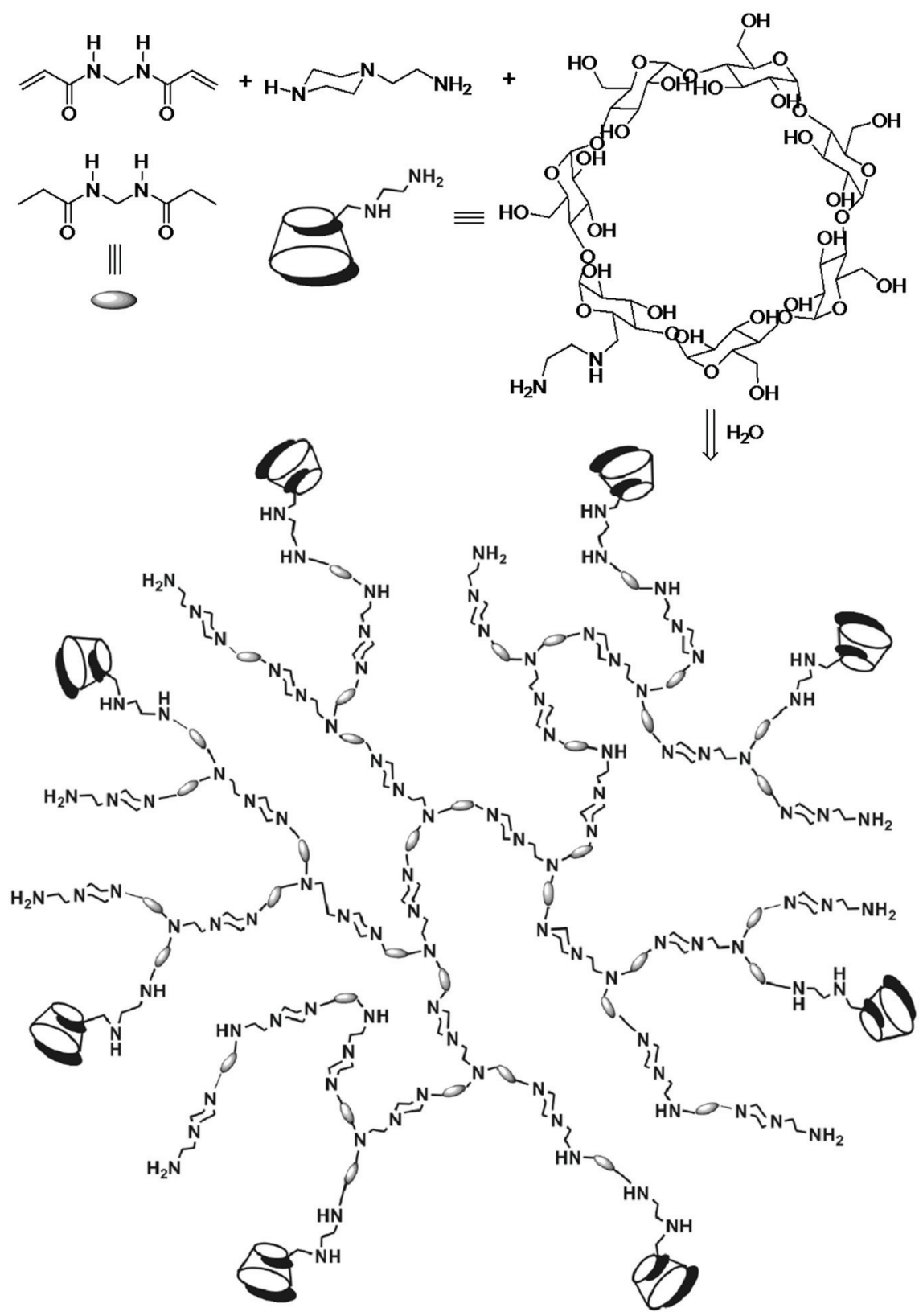

图 9 用 $\beta$-环糊精 $(\beta-\mathrm{CD})$ 修饰的 $h b$-PAMAM 的结构示意图 ${ }^{[19]}$

Figure 9 An illustration of the $\beta$-cyclodextrin-modified $h b$-PAMAM ${ }^{[19]}$

超支化聚醚酰胺 [hyperbranched poly(ether amide)s, $h b$-PEAs]. 他们观察到的 $h b$-PEAs 的发光行为可以总结 如下: (1) 与见诸报道的 $h b$-PAMAM 和 $h b$-PAE 相似, $h b$-PEAs 也发射蓝色苂光, 但是发射波长较短, 在 388 $\mathrm{nm}$ 激光激发下, 发射峰值波长为 $423 \mathrm{~nm}$; (2) $h b$-PEAs 分子量增大, 荧光强度上升, 而苂光发射波长不变, 这 与其它体系也相似; (3) 只有 $h b$-PEAs 才观察到苂光, 而 线形 PEAs 没有苂光; (4) 当 $h b$-PEAs 的羟基与异丙基丙 烯酰胺结合后, 外围修饰了温敏性聚异丙基丙烯酰胺的 $h b$-PEAs 仍旧保持较强的蓝色荧光并且发光峰位有所 红移. 依据这些实验结果, 作者推测 $h b$-PEAs 的苂光与 聚合物超支化的拓扑形态有关, 拥挤的空间结构和特殊 的基团排布方式一方面有利于分子内氢键的形成，另一
方面增大了链刚性，限制了基团的运动，这些因素都减 弱了生色团的非辐射衰变过程.

2012 年初, 葡萄牙里斯本大学化学系的 Bonifácio 博士及其合作者 ${ }^{[25]}$ 报道了一种富含叔胺基团的树枝状 聚脲的发光行为和生物可降解特性. 他们在超临界条件 下在双(三甲基硅)乙酰胺(BSA)的存在下先将三乙胺胺 (TREN) 与 $\mathrm{CO}_{2}$ 进行反应, 产生氨基甲酸酯中间体 $\mathbf{1}$, 将 高压釜减压后加入过量 TREN 和 BSA，加热到 $120{ }^{\circ} \mathrm{C}$ 反 应一段时间，得到第一代树枝状聚嫝(PURE-G1); 重复 这个过程可以定量地得到高代数的 PURE-G $n(n=2,3$, 4) (图 12). 该聚腿的发光行为与超支化和树枝状 PAMAM 相似，都具有在低 $\mathrm{pH}$ 值(酸性条件)下苂光增强 的性质，但是在不同 $\mathrm{pH}$ 值下，以腿单元为基本单位的 


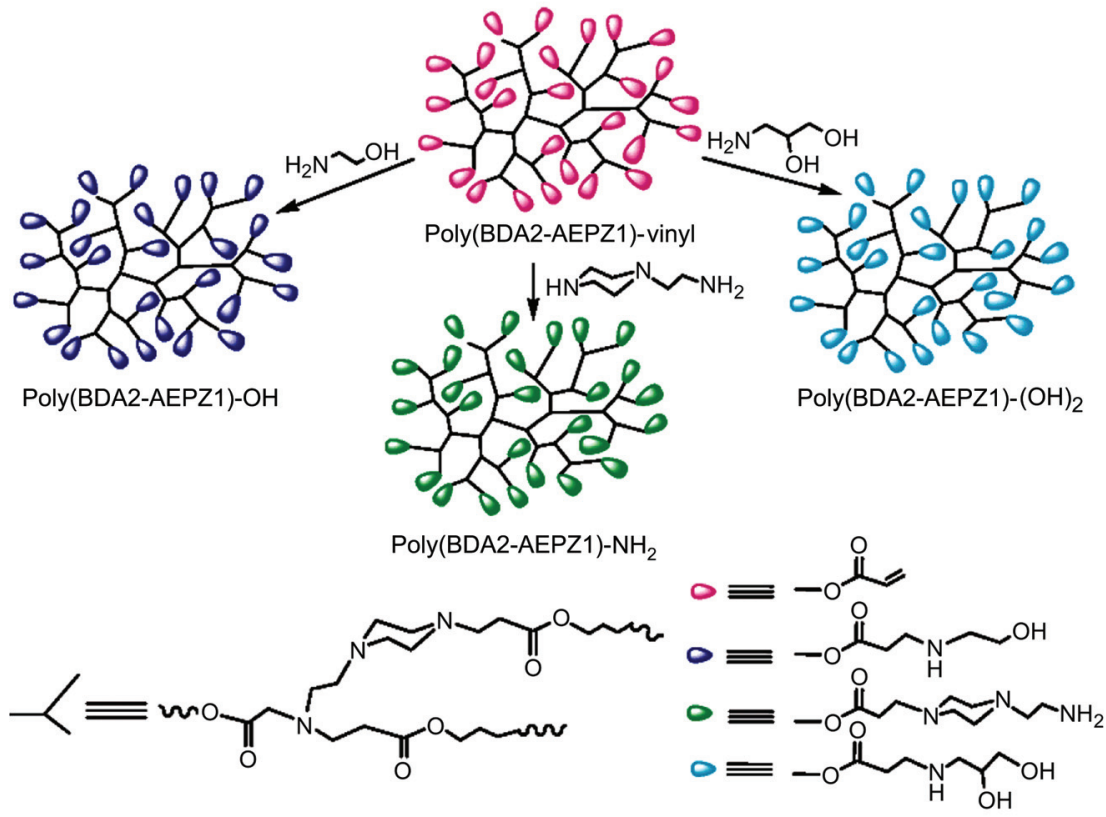

图 10 带不同外围官能团(氨基、羟基、双羟基)超支化聚氨基酯的结构与合成路线示意图 ${ }^{[20]}$

Figure 10 Reaction scheme for preparing hyperbranched poly(amino ester)s with different terminal groups ${ }^{[20]}$

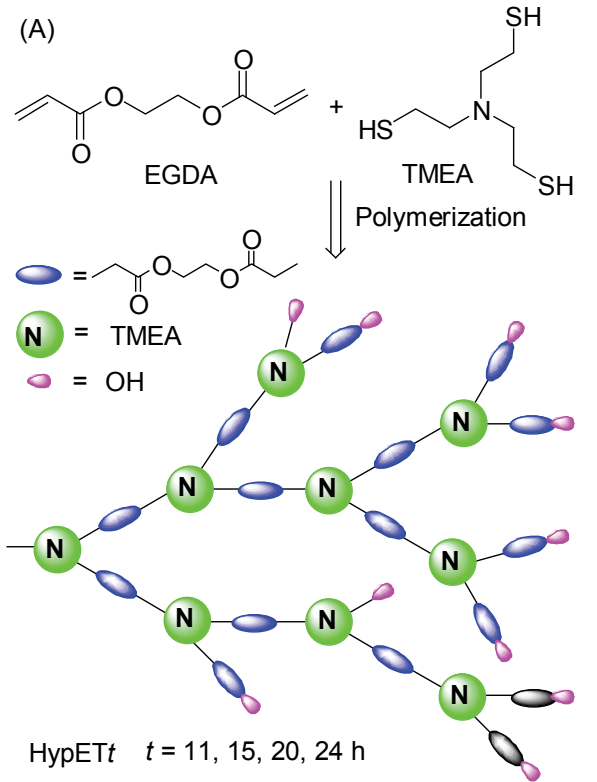

\section{(B)}

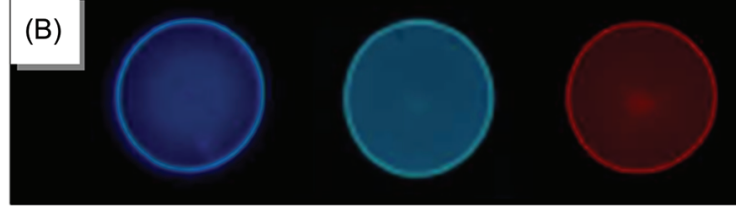

图 11 (A) 含巯基的超支化聚氨基酯的合成路线示意图. (B)超支化 聚氨基酯形成的环状薄膜在不同激发波长范围内的荧光照片: (左)普 通紫外灯下; (中)激发波长范围 330 385 nm; (右)激发波长范围 510 $550 \mathrm{~nm}$

Figure 11 (A) Synthesis of the hyperbranched polymer HypET. (B) Optical fluorescence microscope photos of the ring-shape films prepared respectively by evaporating a drop of the HypET24 solution (left) and HypET24-O20 solutions in $\mathrm{CHCl}_{3}$ on the clean glass slides under excited wavelength of $330 \sim 385 \mathrm{~nm}$ (middle); and $510 \sim 550 \mathrm{~nm}$ filters (right)
定量测试结果表明苂光并没有随着代数增大而增强，因 此苂光增强并没有树枝化效应. 对人类纤维原细胞的毒 理实验结果表明，该聚脲在很宽浓度下都表现出很低的 细胞毒性，而且共聚焦荧光显微镜照片显示聚艮容易穿 过细胞膜和核膜，因此在细胞核内观察到亮蓝色荧光， 说明这种荧光型聚脲有望作为安全性的基因载体. 这个 工作的重要价值在于提供了一种简便、经济、快速、定 量地合成水溶性的、可生物降解的、细胞毒性低的、可 用自体苂光进行示踪的聚合物.

\section{4 以羰基为核心的聚合物体系}

在前面例举的研究实例中, 各种聚合物都涉及脂肪 胺,一个越来越被认同的机理是脂肪族叔胺的氧化, 形 成荧光发射中心, 即荧光生色团; 而台湾国立健康研究 院的 Lin 等 ${ }^{[11]}$ 最近明确地提出脂肪族羟胺是发光中心. 李悦生研究员等 ${ }^{[24]}$ 报道的聚醚酰胺体系也没有排除叔 胺基团的存在. 但是, 在以 PAMAM 为主的含脂肪胺官 能团的聚合物之外，一些不含叔胺、甚至不含 $\mathrm{N}$ 原子的 聚合物也先后被报道有苂光发射现象。这些体系拥有两 个显著特点，一是在这些聚合物结构中不含叔胺基，而 都含羰基(或酯基); 二是这些聚合物在稀溶液中都检测 不到苂光，而只有在固态下或者粘稠液体中才能观察到 明显的荧光, 行为颇似近年来形成研究热点的聚集诱导 发光材料 ${ }^{[26 ~ 28]}$.

2007 年, 香港科技大学唐本忠教授课题组 ${ }^{[29,30]}$ 报道 了马来酸酤与醋酸乙烯酯交替共聚物(图 13A)的苂光发 射现象. 尺寸均匀的共聚物微胶粒可以通过简单的无稳 定剂分散聚合制得(图 13B，C)，共聚物为胶粒悬浮液 

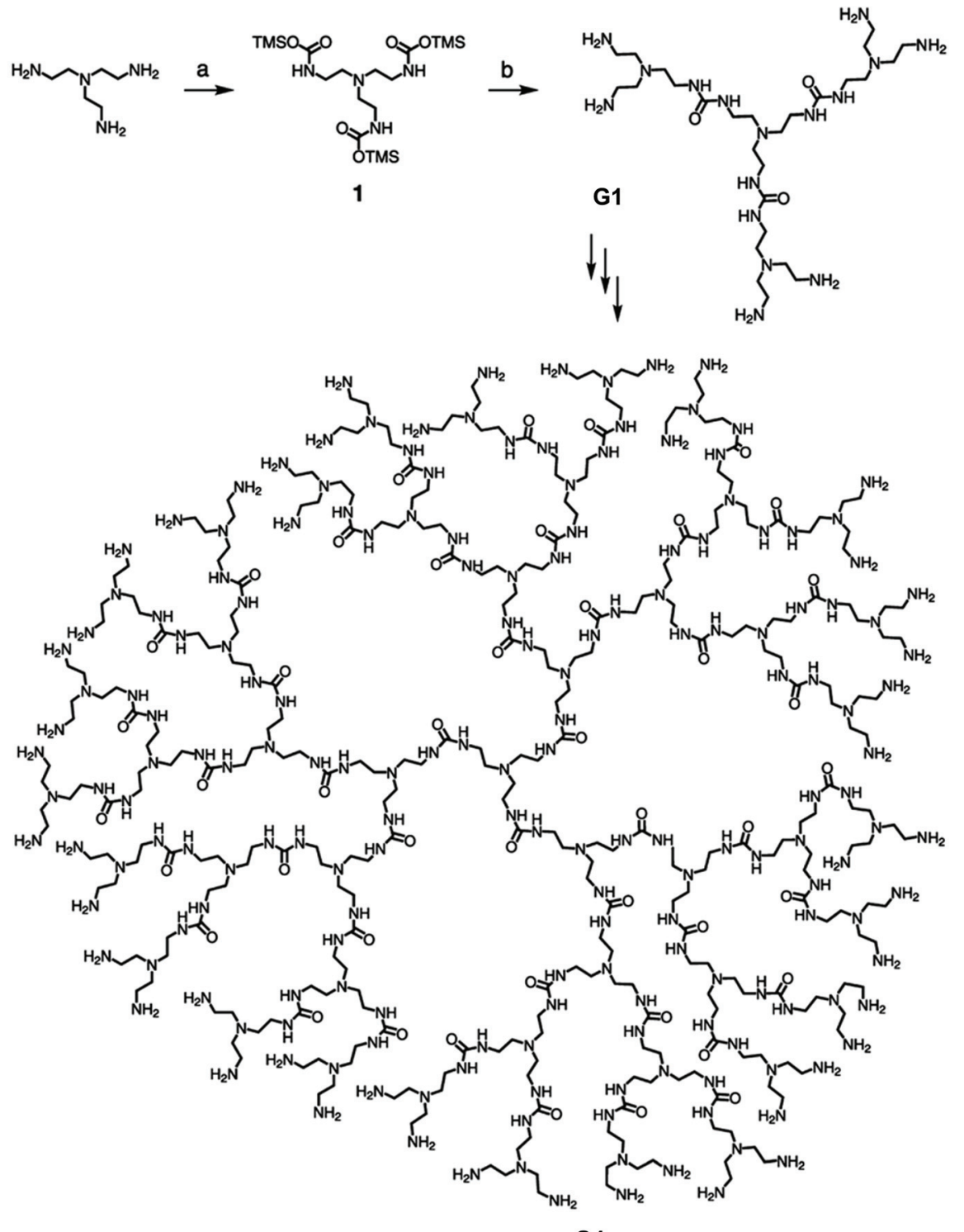

G4

图 12 在超临界 $\mathrm{CO}_{2}$ 中合成带端氨基的超支化聚腿的路线图. 反应条件: (a)超临界 $\mathrm{CO}_{2} ; \mathrm{BSA}, 18.5 \mathrm{MPa}, 40{ }^{\circ} \mathrm{C}, 20 \mathrm{~h} ;(\mathrm{b}) \mathrm{BSA}, \mathrm{TREN}, 120{ }^{\circ} \mathrm{C}, 17 \mathrm{~h}$. $\mathrm{TMS}=$ 三甲基硅 ${ }^{[25]}$

Figure 12 Synthesis of polyurea dendrimers with terminal amino groups in supercritical $\mathrm{CO}_{2}$. Experimental conditions: (a) supercritical $\mathrm{CO}_{2}, \mathrm{BSA}, 18.5$ $\mathrm{MPa}, 40{ }^{\circ} \mathrm{C}, 20 \mathrm{~h}$; (b) BSA, TREN, $120{ }^{\circ} \mathrm{C}, 17 \mathrm{~h}$. TMS $=$ trimethylsily $\left[{ }^{[25]}\right.$

在紫外灯照射下发出蓝紫色苂光(图 13D). 光谱测试结 果表明: 在波长为 $338 \mathrm{~nm}$ 的紫外光激发下, 溶剂为乙酸 丁酯的悬浮液发射出峰值为 $419 \mathrm{~nm}$ 的蓝紫光. 当溶剂 换为二氧六环和四氢呋喃时, 发射峰红移到 428 和 432 $\mathrm{nm}$ 附近. 而在水和乙醇介质中, 微胶粒悬浮液没有苂 光. 有趣的是, 在 $N, N$-二甲基甲酰胺、 $N$-甲基吡咯烷酮 和二甲基亚砜等强极性溶剂中, 悬浮液呈紫红色; 在波 长为 391 和 $551 \mathrm{~nm}$ 的光激发下, 分别发射出峰值为 477 和 $615 \mathrm{~nm}$ 的蓝光和红光. 稍后, 意大利比萨大学 Pucci 课题组 ${ }^{[31]}$ 报道了聚异丁烯丁二酸酐和聚异丁烯丁二酰 亚胺的聚集诱导发光现象. 2008 年, 法国科学院院士 Lehn 研究小组 ${ }^{[32]}$ 报道了组成动态高分子的一些多糖在
聚集状态下的奇特发光现象.

最近, 中国科学院化学研究所胶体与界面科学重点 实验室李峻柏研究员等 ${ }^{\left[{ }^{3}\right]}$ 报道了用多糖藻酸二醛与胱 胺二盐酸盐通过共价交联制备的层层组装微胶囊的自 体苂光. 形成的结构中存在席夫碱, 其吸收谱带在 211 $\mathrm{nm}$ 和 $340 \mathrm{~nm}$ 处有两个峰, 分别对应席夫碱的 $\pi \rightarrow \pi^{*}$ 和 $\mathrm{n} \rightarrow \pi^{*}$ 跃迁. 用 $405 \mathrm{~nm}$ 波长的光源激发聚合物时, 荧光 峰位在 $480 \mathrm{~nm}$ 附近, 而用不同接受窗口可以在共聚焦 荧光显微镜下观察 $425 \sim 475 \mathrm{~nm}$ 的蓝色荧光, 500 5 50 $\mathrm{nm}$ 的绿色荧光和 $600 \sim 650 \mathrm{~nm}$ 的红色荧光, 作者把观 察到的荧光归属为席夫碱结构的 $\mathrm{n} \leftarrow \pi^{*}$ 跃迁.

荷兰埃因霍温理工大学复杂分子系统研究所 
A<smiles>CC(=O)OC(CC1C(=O)OC(=O)C1(C)C)C(C)(C)C</smiles>

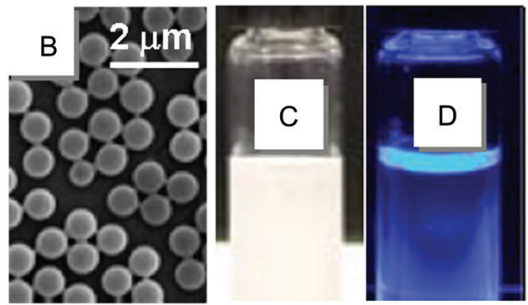

图 13 (A)马来酸酐与醋酸乙烯酯交替共聚物的化学结构. (B)共聚物 微胶粒的扫描电镜图像, 标尺为 $2 \mu \mathrm{m}$. (C) 和(D)分别为共聚物悬浮液 在日光和 $365 \mathrm{~nm}$ 紫外光下的照片 ${ }^{[29]}$

Figure 13 (A) Chemical structure of poly[(maleic anhydride)-alt-(vinyl acetate)]. (B) A typical SEM image of the copolymer colloids, scale bar: $2 \mu \mathrm{m}$. (C) and (D) Photographs of the suspension taken under the illumination of daylight and $365 \mathrm{~nm}$ UV light, respectively ${ }^{[29]}$

Sijbesma 研究小组 ${ }^{[34]}$ 报道了在聚合物主链引入 1,2 -二环 氧烷单元而带来机械诱导化学荧光的创新工作. 自然界 存在多种将通过机械化学转换实现诸如视、听和细胞粘 附等功能的途径, 但是在分子水平上在合成材料中把力 转换成光仍然是巨大的挑战. 如图 13 所示, 当把适当的 力施加到含有双(金刚烷基)-1,2-二环氧烷单元的聚合物 链或者聚合物网络之上时, 双(金刚烷基)-1,2-二环氧烷 发出可见光. 对含二环氧烷的线性聚合物溶液超声或者 使用二环氧烷交联的聚合物网络发生应变, 都能观察到 亮蓝色荧光(图 14). 他们认为发光来自于金刚烷酮的激 发态, 这些研究结果可以帮助我们理解和认识来自不含 叔胺基团的非共轭聚合物的荧光发射现象. 不仅如此, 作者还展示: 通过能量转移到合适的荧光受体可以提高 灵敏度和调节发光颜色, 高时空分辨率将使人们能够在 前所未有的细节上研究聚合物材料的失效.

中国科技大学洪春雁教授和尤业字教授 ${ }^{[35]}$ 合作在 2012 年 8 月份报道了不引入苂光基元通过非荧光单体 制备强苂光聚合物的工作. 他们用邻二芐与全硫代碳酸 根阴离子通过缩聚反应制成聚(全硫代碳酸酯), 并以此 作为 RAFT 试剂引发不同丙烯酸酯和丙烯酰胺的聚合, 得到一系列聚合物(图 15). 在 $280 \mathrm{~nm}$ 的紫外光激发下, 这些聚合物溶液在四氢呋喃溶液中发射出峰值为 410 $\mathrm{nm}$ 的蓝紫光, 苂光强度随着聚合反应时间的延长和分 子量的增大而增强. 基于仔细的结构分析和理论模拟, 他们认为: 被周围聚合物线团纳米结构分隔的苯环单元 与邻近的羰基之间的 $\pi-\pi$ 相互作用是导致荧光发射的原 因. 这项研究在原有的叔胺基团和羰基的不含经典生色 团的苂光聚合物体系的基础上，把可能的化学结构进一 步拓展，提供了一条用不含任何荧光生色团(包括单体、 引发剂和链转移剂)的化合物制备荧光聚合物的合成路 线, 将对今后设计合成这类荧光聚合物产生重要影响.

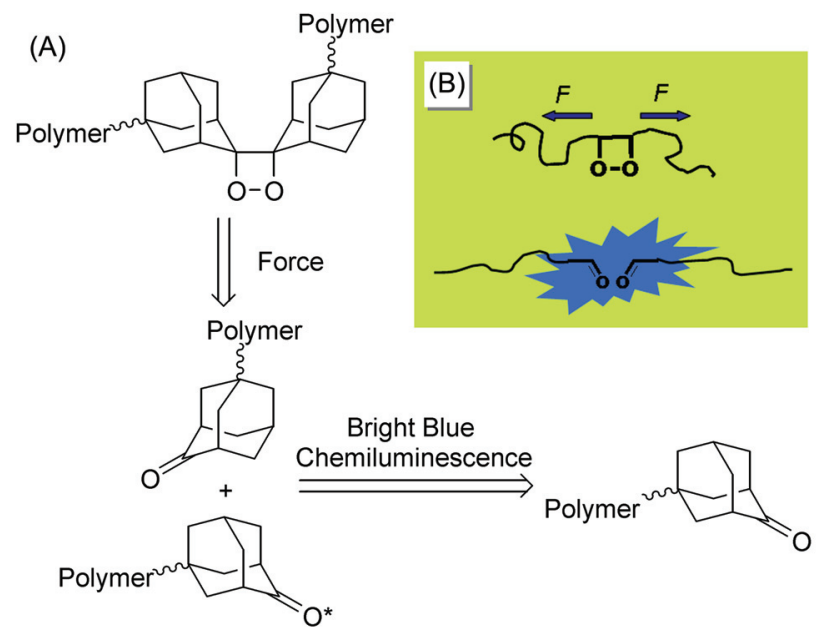

图 14 (A)机械力诱导含双金刚烷基-1,2-二环氧烷的聚合物解体并导 致化学荧光发射的示意图. (B)机械诱导化学苂光发射的概念图 ${ }^{[34]}$

Figure 14 (A) Schematic representation of the mechanically induced decomposition of a polymeric bis(adamantyl) dioxetane that results in chemiluminescence when the ketone product relaxes from its excited state to the ground state. (B) Basic concept of the mechanically induced chemiluminescence ${ }^{[34]}$<smiles>CC(C)(C)Cc1ccccc1CSC(=S)SC(C)(C)C</smiles>

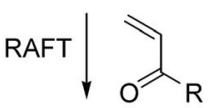

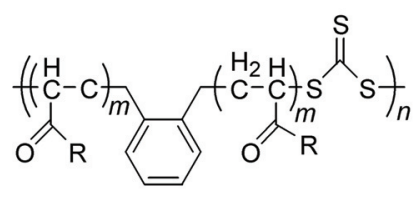<smiles>[R]OCCNC(C)C</smiles>

图 15 聚合物合成路线在左侧, 右侧的截图为反应各个步骤所得产 物对应的苂光照片 ${ }^{[35]}$

Figure 15 Polymer synthesis and the corresponding fluorescence microscope images at each step of the reaction provided on the right

(1) $O$-xylylene dibromide solution in chloroform in a capillary, (2) image of poly(trithiocarbonate) (PTTC) solution in chloroform in a capillary, (3) RAFT polymerization mixture of NIPAM using PTTC as RAFT agent in a capillary ${ }^{[35]}$

\section{5 总结与展望}

综上所述, 含非典型性生色团的苂光聚合物的种类 从最初的合成难度大的树枝状 PAMAM 发展到容易合 成的超支化 PAMAM，从 PAMAM 发展到聚脂肪胺、聚 
脲、聚醚酰胺体系, 再从含叔胺的聚合物体系发展到仅 含羰基或酯基的聚合物体系，这类聚合物已经引起越来 越多的研究者的关注. 由于这类聚合物主要由脂肪链、 胺基、酰胺基、酯基、羰基等化学结构单元组合而成, 在 化学组成上比合成的共轭聚合物荧光材料更接近蛋白 质、多糖等生物大分子, 而这些极性基团同时赋予聚合 物良好的水溶性, 因此这类聚合物显示出更好的生物相 容性、更低的细胞毒性、更强的细胞内吞能力等优越性 能. 这些优点已经在最近三年报道的高水平的研究工作 中得到明确体现, 而且将在今后的研究中得到更加充分 的展示.

根据这类聚合物的结构特点和前期工作基础，以下 几方面可能成为今后的研究重点. (1)发展出更多的含非 典型性生色团的荧光聚合物的种类, 探索出简便、可控 的制备路线, 供光电功能、生物医学领域的研究者使用 和借鉴. (2) 与共轭聚合物发光材料相比, 这类材料的苂 光量子产率偏低, 而且发光集中在蓝光区域. 虽然一些 聚合物可以发红光, 但是效率很低, 这会限制其在生物 成像领域的应用. 深入研究这类聚合物发光的机理, 以 获得更高效率、更长波长的发光, 是一个重要课题. (3) 这类聚合物的荧光和若干生物组织的自体荧光接近, 我 们推测对这类聚合物在不同聚集状态下和不同环境中 发光行为的精细的、系统的对比研究结果将有助于理解 生命组织自体苂光代表的生物学意义, 甚至可能发展出 一种相应的医学诊疗手段.

\section{作者简介}

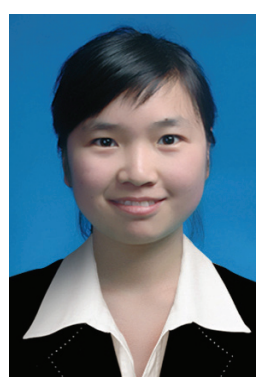

黄田, 女, 汉族. 2010 年 7 月毕业于中南民族大学材料化 学系, 获工学学士学位. 同年 9 月进入浙江大学高分子科学与 工程学系攻读硕士学位, 开展含非典型性荧光生色团的超支 化聚酰胺胺的合成与发光机理研究.

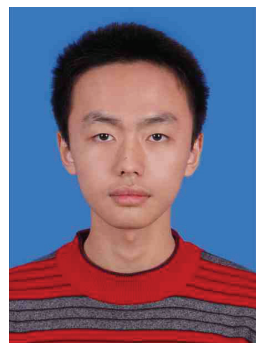

汪昭旸, 男, 汉族. 2009 年 8 月进入浙江大学学习, 2010 年 9 月进入高分子科学与工程学系, 2012 年 9 月获得直接攻读
博士学位资格, 研究方向为含非典型性生色团的发光聚合物 的设计合成与应用。

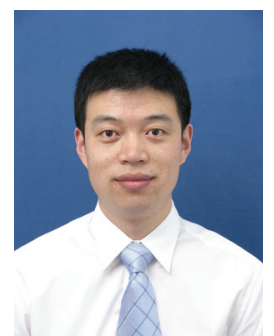

秦安军, 汉族. 2004 年在中国科学院化学所获得博士学位, 2005 至 2008 年先后在香港科技大学化学系唐本忠教授课题组 和浙江大学高分子科学与工程学系做博士后研究, 出站后留 校任教并于 2008 年晋升副教授, 2012 年获得国家自然科学基 金委优秀青年科学基金资助。研究兴趣包括用三键模块构建 线形与超支化聚合物，特别关注新催化体系与新聚合反应， 探索功能提高与创新的化学方法.

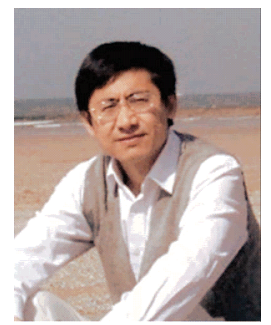

孙景志, 蒙古族. 1986 年 7 月于吉林大学化学系获理学学 士学位, 1986 年 7 月至 1993 年 9 月在辽阳石油化纤公司工作, 1999 年 7 月于吉林大学高分子化学与物理专业获理学博士学 位, 1999 年 9 月至 2001 年 7 月在浙江大学高分子科学与工程 学系做博士后研究, 出站后留校任教, 2001 年晋升副教授, 2006 年晋升教授. 研究领域涉及高分子合成与光电功能构造、 生物电子学和有机/无机半导体杂化材料.

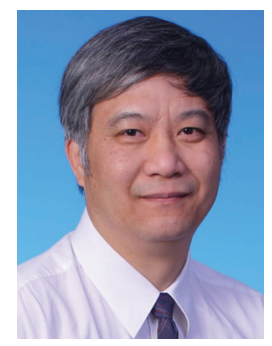

唐本忠, 汉族, 中国科学院院士. 在华南理工大学和日本 京都大学分别获得学士和博士学位; 曾在加拿大多伦多大学 从事博士后研究、日本 NEOS 公司中央研究所任高级研究员. 1994 年入职香港科技大学, 2007 年获国家自然科学二等奖, 装槎基金会高级研究员奖, 2008 年晋升香港科技大学讲座教 授, 2013 年 1 月任张鉴泉理学教授, 2009 年当选中国科学院院 士. 目前任 RSC Polymer Chemistry Series (英国皇家化学会)主 编、Polymer Chemistry (英国皇家化学会)和《化学进展》等期 刊副主编, Prog. Polym. Sci. (Elsevier)等国际期刊编委.

\section{References}

[1] Dong, J. H.; Zhang, X.; Wang, L. X. Frontier and Prospect of Polymer Science, Science Press, Beijing, 2011, pp. 409 485. (董建华, 张希, 王立祥, 高分子科学学科前沿与展望, 科学出版社, 北京, 
2011, pp. 409 485.)

[2] Demas, J. N.; Crosby, G. A. J. Phys. Chem. 1971, 75, 991

[3] Varnavski, O.; Ispasoiu, R. G.; Balogh, L.; Tomalia, D.; Goodson III, T. J. Chem. Phys. 2001, 114, 1962.

[4] Zheng, J.; Petty, J. T.; Dickson, R. M. J. Am. Chem. Soc. 2003, 125, 7780 .

[5] Lee, W. I.; Bae, Y.; Bard, A. J. J. Am. Chem. Soc. 2004, 126, 8358

[6] Wang, D.; Imae, T. J. Am. Chem. Soc. 2004, 126, 13204.

[7] Cao, L.; Yang, W. L.; Wang, C. C.; Fu, S. K. J. Macromol. Sci. Part A: Pure Appl. Chem. 2007, 44, 417.

[8] Wang, D.; Imae, T.; Miki, M. J. Colloid Interface Sci. 2007, 306, 222

[9] Chu, C.-C.; Imae, T. Macromol. Rapid Commun. 2009, 30, 89

[10] Pastor-Pe'rez, L.; Chen, Y.; Shen, Z.; Lahoz, A.; Stiriba, S.-E. Macromol. Rapid Commun. 2007, 28, 1404.

[11] Lin, S.-Y.; Wu, T.-H.; Jao, Y.-C.; Liu, C.-P.; Lin, H.-Y.; Lo, L.-W.; Yang, C.-S. Chem. Eur. J. 2011, 17, 7158.

[12] Saravanan, G.; Imae, T. J. Nanosci. Nanotechnol. 2011, 11, 4838.

[13] Tsai, Y.-J.; Hu, C.-C.; Chu, C.-C.; Imae, T. Biomacromolecules 2011, $12,4283$.

[14] Imae, T.; Hamaguchi, S. Carbohydr. Polym. 2012, 88, 352.

[15] Yang, W.; Pan, C.-Y. Macromol. Rapid Commun. 2009, 30, 2096.

[16] Yang, W.; Pan, C.-Y.; Luo, M.-D.; Zhang, H.-B. Biomacromolecules 2010, 11, 1840.

[17] Yang, W.; Pan, C.-Y.; Liu, X.-Q.; Wang, J. Biomacromolecules 2011, $12,1523$.

[18] You, Y.-Z.; Yu, Z.-Q.; Cui, M.-M.; Hong, C.-Y. Angew. Chem. Int. Ed. 2010, 49, 1099.

[19] Chen, Y.; Zhou, L.; Pang, Y.; Huang, W.; Qiu, F.; Jiang, X.; Zhu, X.
Y.; Yan, D.; Chen, Q. Bioconjugate Chem. 2011, 22, 1162.

[20] Wu, D. C.; Liu, Y.; He, C. B.; Goh, S. H. Macromolecules 2005, 38 , 9906.

[21] Wu, D. C.; Liu, Y.; Chen, L.; He, C. B.; Chung, T. S.; Goh, S. H. Macromolecules 2005, 38, 5519.

[22] Sun, M.; Hong, C.-Y.; Pan, C.-Y. J. Am. Chem. Soc. 2012, 134 20581.

[23] Halpern, A. M.; Wryzykowska, K. J. Photochem. 1981, 15, 147.

[24] Liu, Y.; Gao, J.-W.; Liu, H.-W.; Li, Y.-S. Macromolecules 2009, 42, 3237.

[25] Restani, R. B.; Morgado, P. I.; Ribeiro, M. P.; Correia, I. J.; AguiarRicardo, A.; Bonifácio, V. D. B. Angew. Chem. Int. Ed. 2012, 51, 5162.

[26] Hong, Y.; Lam, J. W. Y.; Tang, B. Z. Chem. Soc. Rev. 2011, 40, 5361.

[27] Zhang, S.; Qin, A.; Sun, J. Z.; Tang, B. Z. Prog. Chem. 2011, 23, 623.

[28] Hong, Y. N.; Lam, J. W. Y.; Tang, B. Z. Chem. Commun. 2009, 4332.

[29] Xing, C. M.; Lam, J. W. Y.; Qin, A. J.; Dong, Y. Q.; Haussler, M.; Yang, W. T.; Tang, B. Z. Polym. Mater. Sci. Eng. 2007, 96, 418.

[30] Qin, A.; Lam, J. W. Y.; Tang, B. Z. Prog. Polym. Sci. 2012, 37, 182.

[31] Pucci, A.; Rausa, R.; Ciardelli, F. Macromol. Chem. Phys. 2008, $209,900$.

[32] Ruff, Y.; Lehn, J.-M. Angew. Chem. Int. Ed. 2008, 47, 3556.

[33] Gao, L.; Fei, J. B.; Zhao, J.; Cui, W.; Cui, Y.; Li, J. B. Chem. Eur. J. 2012, 18,3185 .

[34] Chen, Y.; Spiering, A. J. H.; Karthikeyan, S.; Peters, G. W. M.; Meijer, E. W.; Sijbesma, R. P. Nat. Chem. 2012, 4, 559.

[35] Yan, J.-J.; Wang, Z.-K.; Lin, X.-S.; Hong, C.-Y.; Liang, H.-J.; Pan, C.-Y.; You, Y.-Z. Adv. Mater. 2012, 24, 5617.

(Cheng, B.) 